\section{Europe implements package deals for space station}

Sally Goodman, Paris

Industrial researchers wanting to use the International Space Station (ISS) are being offered cut-price passage by the European Space Agency (ESA). The agency is offering rack space attached to the craft at prices from US $\$ 60,000$ per day.

ESA officials think they can attract commercial customers - who might want to use the gravity-free station for anything from materials research to drug development - by offering a more accessible and tailored service than NASA.

NASA only offers full equipment racks containing about one cubic metre of space in its Destiny laboratory for $\mathbf{\$ 2 0 . 8}$ million for a full year. But at the ISS Forum 2001 in Berlin earlier this month, ESA published its price list, offering smaller lockers on its Columbus laboratory for as little as three months, with rates starting at $\$ 715,000$ for that period. External racks can be used for even shorter periods, at $\$ 60,000$ per day. The facilities should be available from 2005.

Jochen Graf, head of the ESA department responsible for selling commercial access, insists that the agency is not competing with NASA. "We are trying to expand the market and to move away from the classic space-science and industry customers," he says. European customers want smaller racks and time slots, Graf adds. "Three months is a good time period for customers using biological material who may want to bring down fresh material at regular intervals," he says.

ESA and NASA have each allocated $30 \%$ of their laboratory space to commercial customers. The European agency recently signed a $\$ 1.7$ million, four-year contract with Intospace, a company based at Hannover in Germany, to market the station to commercial users.

Graf said that, although European companies would be its main target, ESA was open to proposals from all over the world, including offers from public-private partnerships. He added that a request could be passed on to one of the other ISS partner agencies if ESA could not handle it.

The Russian Space Agency also plans to provide a competitive commercial package on the station. Russia expects to be able to take experiments there more cheaply using its Soyuz or Proton rockets than either NASA or ESA will be able to do on the US space shuttle. S.G.

http://www.esa.int/spaceflight/isscommercialisation

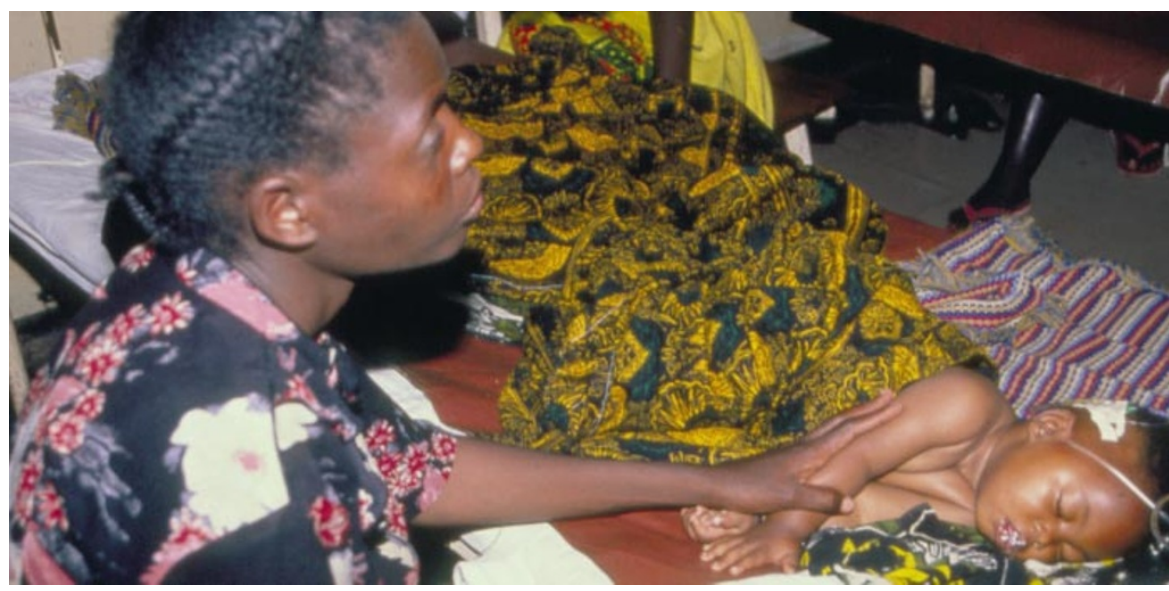

Crisis point: countries facing killer diseases such as malaria want freedom from drug patent rules.

\title{
Poor nations push for right to produce cheap medicines
}

Sally Goodman, Paris

The United States clashed with developing countries over the impact of global trading rules on the distribution of medicines, at a special meeting of the World Trade Organization (WTO) in Geneva, Switzerland.

The meeting on 20 June, called by the WTO's African members, looked at whether the agreement known as TRIPS (trade-related aspects of intellectual property rights) should be modified to allow poorer countries better access to affordable drugs. TRIPS is aimed at protecting intellectual property rights internationally.

Officials said afterwards that, despite broad differences on the issue between developing countries and the United States in particular, further discussions would be held in the hope that global trade ministers can produce a clear statement on the issue when they meet in Qatar this November.

Pharmaceutical companies have argued, for example, that the TRIPS agreement entitles the United States to charge Brazil with breaching WTO rules by manufacturing its own generic AIDS drugs. The United States has so far refrained from taking such action.

According to the current TRIPS agreement, with which all WTO members must comply by 2006, compulsory licensing — the production of cheaper, generic versions of a drug _ can take place without the prior consent of the patent holder only "in national emergencies or other circumstances of extreme urgency".

The developing countries want the WTO to state clearly that this allows them to act freely in responding to AIDS and other health crises. Otherwise, they say, TRIPS may have to be changed. They also want more time to comply with the agreement.

Delegates from European Union countries also urged clarification on some points of TRIPS. They called for more discussion to produce a consensus on how it should be interpreted.

The US delegation said that it "would not object" if WTO member countries used the flexibility within the agreement to tackle major health crises. But it warned against the use of practices such as compulsory licensing "in the normal course of doing business". The delegation denied that the TRIPS agreement is not sufficiently clear or flexible.

David Earnshaw of Oxfam International says the outcome of the meeting was "entirely satisfactory" and has "shown up the United States as completely isolated in its position". Francisco Cannabrava, the Brazilian delegate, although critical of what he regards as the United States' inflexible reading of the TRIPS agreement, welcomed the fact that they were participating in the discussion.

But Harvey Bale, director-general of the International Federation of Pharmaceutical Manufacturers Associations, warned that developing countries, and not the pharmaceutical companies, could be the biggest losers if changes were made to TRIPS. "The world needs to decide where it wants pharmaceutical companies to put their R\&D," he says. "There are lots of diseases with currently ineffective treatments where they could put their money instead."

Many countries and non-governmental organizations now hope that a declaration will be agreed in Qatar stating that the TRIPS agreement should not stand in the way of public-health agendas. They say this will help to stave off growing public criticism that the WTO is indifferent to the needs of poor countries. As a result of last week's meeting, two further WTO meetings on access to medicines have already been planned for between now and November .

http://www.wto.org 